\title{
Immunohistochemical Comparison of p53, Ki-67, CD68, Vimentin, $\alpha$-smooth Muscle Actin and Alpha-1-Antichymotry- psin in Oral Peripheral and Central Giant Cell Granuloma
}

\author{
1Omar Kujan, ${ }^{2}$ Ahmad Zahi Al-Shawaf, ${ }^{3}$ Saleh Azzeghaiby, ${ }^{4}$ Ahmad AlManadille, ${ }^{5}$ Kusay Aziz, ${ }^{6}$ Syed Ahmed Raheel
}

\begin{abstract}
Introduction: Giant cell lesions are characterised histologically by multinucleated giant cells in a background of ovoid to spindleshaped mesenchymal cells. There is a major debate whether these lesions are separate entities or variants of the same disease. Our aim was to study the nature of multinucleated and mononuclear cells from peripheral giant cell granuloma (PGCG), and central giant cell granuloma (CGCG) and giant cell tumor (GCT) of long bones using immunohistochemistry evaluation and to determine whether there is a correlation between recurrence and the markers used.
\end{abstract}

Materials and methods: Ki-67, p53, Vimentin, smooth muscle specific actin, CD68 and alpha-1-antichymotrypsin were used to study 60 giant cell lesions. These included 26 CGCG, 28 PGCG, and 6 GCT cases using an avidin-biotin-complex immunohistochemistry standard method.

Results: All studied cases showed the same results except the percentage of Ki-67 positive mononuclear cells in PGCG was significantly higher than that of both CGCG and GCT $(p<0.05)$. Interestingly, no statistical correlation between recurrence and the markers used was found.

Conclusion: Our results may suggest that these lesions have the same histogenesis. The mononuclear stromal cells, both histiocytic and myofibroblastic, are thought to be responsible for the behavior of these lesions whereas the multinucleated cells are considered as reactive. This might support the argument that PGCG, CGCG and GCT are different variants for the same disease. Further studies using molecular techniques are required to elucidate why some of these lesions behave aggressively than others.

Keywords: alpha-1-antichymotrypsin, central p53, Ki-67, CD68, giant cell granuloma, immunohistochemistry, peripheral, Vimentin, $\alpha$-smooth muscle actin.

How to cite this article: Kujan O, Al-Shawaf AZ, Azzeghaiby S, AlManadille A, Aziz K, Raheel SA. Immunohistochemical

\footnotetext{
1,3,6 Department of Oral and Maxillofacial Sciences, Unit of Skills Development and Continuing Education, Al-Farabi College for Dentistry and Nursing, Riyadh, Saudi Arabia

${ }^{2}$ Department of Pathology, Faculty of Medicine, Al-Baath University, Homs, Syria

${ }^{4,5}$ Department of Oral Pathology, Faculty of Dentistry Damascus University, Damascus, Syria
}

Corresponding Author: Omar Kujan, Assistant Professor and Head, Department of Oral and Maxillofacial Sciences, Unit of Skills Development and Continuing Education, Al-Farabi College for Dentistry and Nursing, Riyadh, Saudi Arabia Phone: +966501158867, e-mail: omar.kujan@gmail.com
Comparison of p53, Ki-67, CD68, Vimentin, a-smooth Muscle Actin and Alpha-1-Antichymotrypsin in Oral Peripheral and Central Giant Cell Granuloma. J Contemp Dent Pract 2015; 16(1):20-24.

\section{Source of support: Nil}

Conflict of interest: None

\section{INTRODUCTION}

Mysteries are still shadowing the pathogenesis of oral giant cell lesions, central giant cell granuloma (CGCG) and peripheral giant cell granuloma (PGCG). It is still vague why some of these lesions behave aggressively in a similar pattern to that of giant cell tumor (GCT) of long bones. The debate whether there is a true GCT in the craniofacial skeleton or not is still unresolved.

In an attempt to distinguish the giant cell lesions of the jaws from microscopically similar neoplastic lesions that occurred in the long bones, Jaffe ${ }^{1}$ first introduced the term giant cell reparative granuloma to designate these lesions in the oral cavity. Since them, the term 'reparative granuloma' was accepted worldwide. However, a criticism was pointed out for using the misleading adjective 'reparative' as some giant cell granulomas show recurrence and appear to be of a destructive nature. As a result, the term 'reparative granuloma' is no longer used. Moreover, Waldron and Whitaker (1993) suggested that replacement of the term 'giant cell granuloma' with 'giant cell lesion' would be more close to an authentic description of these lesions. ${ }^{2}$

Central giant cell granuloma, peripheral giant cell granuloma and giant cell tumor have a common histological features outlined by multinucleated giant cells in a background of ovoid to spindle-shaped mesenchymal cells. ${ }^{3,4}$ Conversely, these lesions showed a wide spectrum of biological behavior from indolent and slow-growing to rapidly growing and destructive. ${ }^{5}$

It is well-known that GCT is mainly a benign but aggressively osteolytic lesion that typically affects the epiphysis, with or without metaphyseal extension, of long bones. ${ }^{6}$ In the jaws, CGCG showed a benign but variable clinical behavior and unpredictable course. ${ }^{2,5}$ Peripheral 
giant cell granuloma is characterised by a constant course with a low rate of recurrence. ${ }^{7,8}$

There was an argument that CGCG is behaviorally identical to some extent to the benign giant cell tumor of long bones suggesting that these lesions are variants of the same disease. ${ }^{4}$ On the contrary, GCT was considered as a true neoplasm while CGCG as a reactive lesion. ${ }^{1}$ At the same time, a debate whether PGCG is either a distinct entity or a peripheral variant of CGCG remains. ${ }^{9}$

It is well accepted that prediction of the behavior of these lesions using histological means is difficult. ${ }^{10}$ However, Waldron and Whitaker ${ }^{2}$ produced a list of features that identified cases that were significantly different between recurrent and nonrecurrent and aggressive and nonaggressive ones. Several attempts to use immunohistochemical staining to study the role/ function of the giant cells and the mononuclear cells in these lesions have been performed. ${ }^{11-14}$ Once again, these studies partially defined the function and phenotype of both the mononuclear cellular component and the giant cells component. Strong evidence suggested that giant cells are osteoclast-like cells. ${ }^{15,16}$ In contrast, others proposed that giant cells are reactionary components of the stromal mononuclear phagocytic cells. ${ }^{11,13}$

In the present study, we tried to resolve the uncertainty of the nature and role of both giant cells and mononuclear cells in CGCG, PGCG and GCT using specific immunohistochemical markers. A second objective was to correlate between the immuno-profile of these lesions and the clinical behavior.

\section{MATERIALS AND METHODS}

The Institutional Review Board has provided a favorable ethical approval (IRB-12-037).

\section{Case Selection}

This is a retrospective study. Tissue samples were retrieved from the archives of the Department of Oral Pathology, Faculty of Dentistry, Damascus University and the Department of Oral Pathology and Medicine, Faculty of Dentistry, Al-Baath University. Sixty formalin-fixed paraffin-embedded tissue blocks were retrieved: twentyeight peripheral giant cell granuloma, 26 central giant cell granuloma and six giant cell tumors of long bones (femur). A standard hematoxylin-eosin histological examination was done to confirm the diagnosis of each case. Clinical information (age, gender, site, size) on each case including follow-up assessment for 30 months was obtained.

\section{Immunohistochemical Methods}

An avidin-biotin-complex immunohistochemistry standard method was used. For the immunohistochemical study, $4 \mu \mathrm{m}$-thick sections were cut from paraffin blocks. Paraffin sections on silane-coated slides were dewaxed with xylene and rehydrated through a graded alcohol concentrations. Then, endogenous peroxidase activity was blocked in absolute methanol solution containing 1\% hydrogen peroxidase for 30 minutes, and the slides were washed in $10 \mathrm{~m}_{\mathrm{M}}$ PBS (pH 7.4). For antigen retrieval, the slides were immersed in $0.1 \mathrm{M}$ citrate phosphate buffer and microwaved at $100^{\circ} \mathrm{C}$ for 15 minutes after the buffer had cooled, normal horse serum was reacted with the slides for 15 minutes to eliminate non-specific immunostaining. The slides were reacted with various primary antibodies overnight at $4^{\circ} \mathrm{C}$ in a humidified chamber. The details of the primary antibodies used in this study were as follows:

Monoclonal antibody MIB-1 for Ki-67 with a dilution of 1:50, monoclonal antibody DO-7 for p53 protein with a dilution of 1:50, polyclonal antibody for alpha-1-antichymotrypsin with a dilution of 1:200, monoclonal antibody EBM11 for CD68 with a dilution of 1:100, monoclonal antibody Vim 3B4 for Vimentin with a dilution of 1:200. monoclonal antibody 1A4 for alpha-smooth muscle actin with a dilution of 1:40. After reaction with a mouse biotinylated secondary antibody, antigen-antibody reactions were visualised using a streptavidin-horseradish peroxidase conjugate (DAKO LSAB kit; DAKO, Los Angles, CA) with diaminobenzidine as the chromogen. All slides were counterstained with haematoxylin. Staining without antibody was performed as a negative control. Positive control was done using standard slides that were purchased from Dako Cytomation, Denmark for each studied marker.

\section{Immunohistochemical and Statistical Analyses}

The immunohistochemical reactivity was evaluated in ten randomly selected high-power fields (400×). The results of immunostaining were scored independently by two observers (O.K and K.A) using consensus on a 4 -point scale. Negative and low $(<10 \%)$ staining scores and moderate (10-50\%) and strong ( $>50 \%)$ staining scores were combined as negative or positive respectively as described previously by Regize et al, $1987{ }^{11}$ Kruskall-Wallis, ANOVA, and $x^{2}$ tests were used for the statistical analysis. All statistical tests are two-sided and p-values less than 0.05 were considered to be statistically significant.

\section{RESULTS}

The clinical and immunohistochemical features of the 60 included lesions are summarized in Tables 1 and 2. 
The age of patients ranged 11 to 67 years with a mean age 31.6. Females were affected more than males (ratio 2:1). Lesions has predilection to mandible than maxilla. Due to missing radiographs from the majority of the examined cases, we were unable to report the radiographic findings.

The selected cases of PGCG, CGCG and GCT for the study showed typical HandE histological features described in the literature. However, the myxoid stromal areas were found more frequently in the GCT and to a lesser degree in the CGCG than that observed in the PGCG. All studied cases showed similar immunostaining findings for the panel used (p53, CD68, alpha-1antichymotrypsin, vimentin and $\alpha$-smooth muscle actin but Ki-67 (Table 2).

In all samples, alpha-1-antichymotrypsin and CD68 (macrophage markers) were widely expressed in both the mononuclear with oval and dendritic profiles and multinucleated giant cells. Most tumor giant cells showed intense nuclear and cytoplasmic reactivity for CD68 (Fig. 1). Smooth muscle specific actin was strongly stained in both the spindle mononuclear cells (myofibroblasts) distributed through the lesion and the mononuclear cells, that supported the abnormal capillary spaces (Fig. 2). Vimentin was widely expressed in the stromal mononu-

Table 1: Summary of the clinical features of the studied cases

\begin{tabular}{llll}
\hline & PGCG & CGCG & GCT \\
\hline Gender (total) & 28 & 26 & 6 \\
$\quad$ Male & $11(39 \%)$ & $8(31 \%)$ & $2(33 \%)$ \\
Female & $17(61 \%)$ & $18(69 \%)$ & $4(67 \%)$ \\
Age & & & \\
$\quad$ Range & $11-67 \mathrm{yr}$ & $13-65 \mathrm{yr}$ & $23-37 \mathrm{yr}$ \\
$\quad$ Mean & $38 \mathrm{yr}$ & $24 \mathrm{yr}$ & $32 \mathrm{yr}$ \\
Location & & & \\
Jaws & & & Long bones \\
$\quad$ Maxilla & $13(46.5 \%)$ & $10(38 \%)$ & Femur 6 (100\%) \\
$\quad$ Mandible & $15(53.5 \%)$ & $16(62 \%)$ & \\
Recurrence & & & \\
Recurrent & $6(22 \%)$ & $7(37 \%)$ & \\
$\quad$ Non-recurrent & $22(78 \%)$ & $19(63 \%)$ & \\
Size & & & \\
$<1.5 \mathrm{~cm}$ & $21(75 \%)$ & $8(31 \%)$ & - \\
$1.5-5 \mathrm{~cm}$ & $7(25 \%)$ & $8(31 \%)$ & $3(50 \%)$ \\
$>5 \mathrm{~cm}$ & - & $10(38 \%)$ & $3(50 \%)$ \\
\hline
\end{tabular}

clear cells both round-shaped and spindle-shaped (Fig. 3). Weak positive staining for vimentin was observed in some giant cells in few cases of CGCG, thus it was categorised as negative/low staining score. Interestingly, the percentage of $\mathrm{Ki}-67$ nuclear positive mononuclear cells in PGCG (Fig. 4A) was significantly higher than that of both CGCG ( $\mathrm{p}=0.014$ ) (Fig. 4B) and GCT ( $\mathrm{p}=0.012$ ) (Table2). PGCG, CGCG and GCT cases selected for the study showed negative staining for p53. There was no correlation between recurrence and the immunohistochemical markers expression in all studied lesions ( $\mathrm{p}=$ 0.31). In addition, no statistical significant correlation was found between the clinical features (gender, age, site) and the recurrence outcome of the examined lesions $(p=0.09)$.

\section{DISCUSSION}

Since Jaffe's defining paper in $1953,{ }^{1}$ the literature has been enriched by studies investigating the distinction between both central giant cell granuloma arising within jaws and peripheral giant cell granuloma arising in oral soft tissues, on one side considered as a reactive lesion and giant cell tumor of long bones on the other side considered as a neoplastic lesion.

Various questions with regard to the histogenesis and clinical associated behavior of PGCG, CGCG and GCT have not been clarified entirely. A debate whether

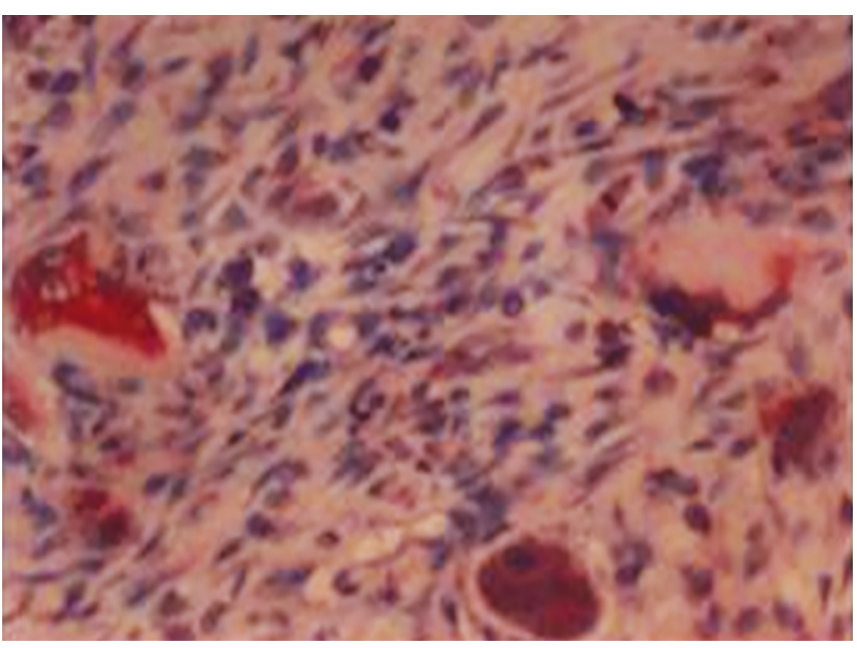

Fig. 1: Immunoreactivity of CD68 expression in both giant and mononuclear cells in CGCG $(\times 200)$

Table 2: Immunoreactivity of markers panel in lesions of PGCG, CGCG and GCT

\begin{tabular}{|c|c|c|c|c|c|c|}
\hline & \multicolumn{2}{|c|}{$P G C G$} & \multicolumn{2}{|c|}{ CGCG } & \multicolumn{2}{|c|}{ GCT } \\
\hline & $G C N(\%)$ & $M C N(\%)$ & GC N(\%) & $M C N(\%)$ & $G C N(\%)$ & $M C N(\%)$ \\
\hline CD68 & $26(92.9)$ & $27(96.4)$ & $24(92.3)$ & $26(100)$ & $6(100)$ & $6(100)$ \\
\hline alpha-1-antichymotrypsin & $26(92.9)$ & $28(100)$ & $24(92.3)$ & $26(100)$ & $6(100)$ & $6(100)$ \\
\hline Vimentin & $0(0)$ & $28(100)$ & $0(0)$ & $25(96.1)$ & $0(0)$ & $5(83.3)$ \\
\hline$\alpha$-smooth muscle actin & $0(0)$ & $20(71.4)$ & $0(0)$ & $18(69.2)$ & $0(0)$ & $4(66.7)$ \\
\hline Ki-67 & $1(3.6)$ & $25(89.3)$ & $0(0)$ & $16(61.5)$ & $0(0)$ & $4(66.7)$ \\
\hline
\end{tabular}

GC: Lesions with positive giant cells; MC: Lesions with positive mononuclear cells; PGCG: Peripheral giant cell granuloma; CGCG: Central giant cell granuloma; GCT: Giant cell tumor of long bones 


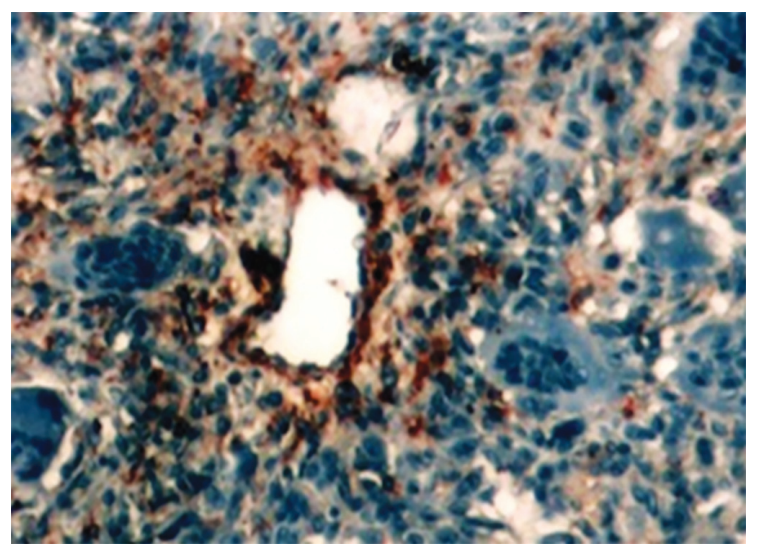

Fig. 2: Immunohistochemical stain for $\alpha$-Smooth muscle actin (myofibroblasts) identifying cells in mononuclear population in peripheral giant cell granuloma (200x)

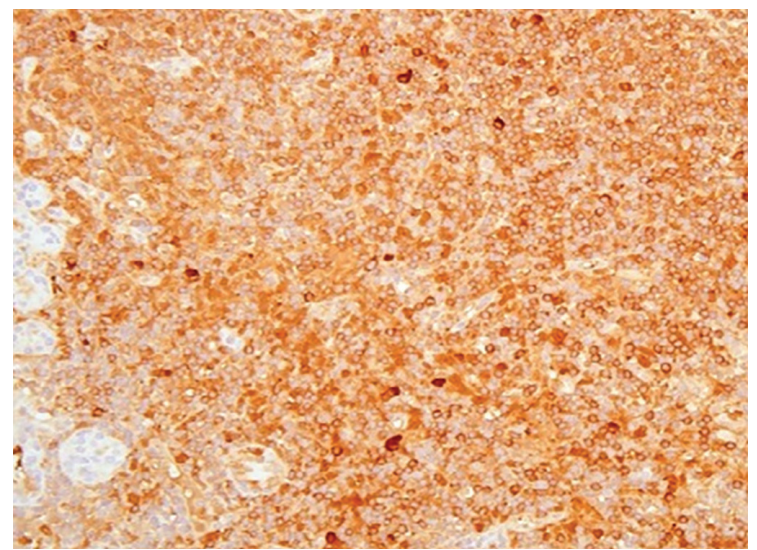

Fig. 3: Vimentin immunoreactivity in central giant cell granuloma (100x)
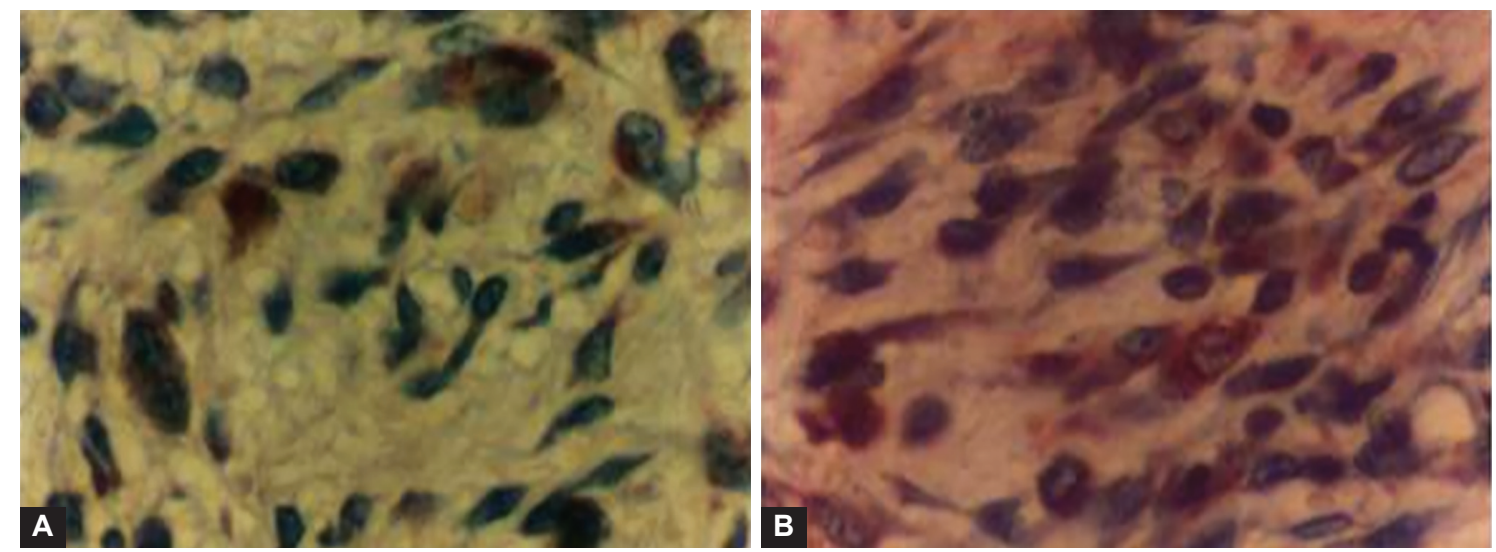

Figs 4A and B: Immunoreactivity of $\mathrm{Ki}-67$ in peripheral giant cell granuloma (400x),

(B) Immunoreactivity of Ki-67 in central giant cell granuloma (400×)

these lesions are variants for the same disease or separate entities is still apposite.

Previous studies investigating the immuno-profile of PGCG, CGCG and GCT have noted that the characterization of both the stromal cell type and the giant cell type need to be fully accomplished. ${ }^{8,10-14,16-18}$

The immunohistochemical staining of the mononuclear cells with vimentin supported that these cells are of mesenchymal origin. Consistently with the studies of Peaccok et al, ${ }^{15}$ and $\mathrm{O}^{\prime}$ Mally et al, ${ }_{1}^{13}$ the immunohistochemical expression of $\alpha$-smooth muscle actin showed that many fibroblasts in CGCG, PGCG and GCT show myofibroblastic differentiation. Moreover, the pattern of distribution of these mononuclear myofibroblastic cells around the abnormal vessel spaces suggested that these cells might play a role in generating of newly formed blood vessels and spaces.

Identification of CD68 and alpha-1-antichemotrypsin immunoreactivity has been used to show macrophage differentiation in several neoplasms. ${ }^{11,19}$ Both populations of cells, giant and mononuclear, showed wide staining for these two markers. This might support that the origin of giant cells are macrophages or are derived from their precursors. However, $\mathrm{O}^{\prime}$ Malley et $\mathrm{al}^{13}$ found small percentage of mononuclear cells stained with CD68 in CGCG suggesting that this marker did nothing to resolve the question whether giant cells are originated from macrophage or osteoclast lineage.

The results showed negative p53 expression in all studied lesions. In addition to that, the percentage of Ki-67 positive mononuclear cells in PGCG was significantly higher than that in both CGCG ( $p=0.014)$ and GCT ( $p=0.012$ ). Only one case of PGCG showed positive $\mathrm{Ki}-67$ staining in the giant cells. However, giant cells in the rest cases of PGCG, CGCG and GCT showed negative immunoreactivity for Ki-67. This finding indicates that giant cells are not involved in the proliferative activity of the lesions. Our results were consistent with other studies. ${ }^{8,13,14}$

In addition, our finding would explain the fact that the aggressiveness of the lesion is promoted by the proliferative activity of mononuclear cells and not giant cells. Literally, de Souza, et a $1^{14}$ state that the differences observed in proliferative activity do not explain the different biological behavior of CGCG and GCT, as reactive lesions may show increased proliferative activity. The authors 
emphasize that since CGCG and GCT occur in different sites, it is difficult to compare accurately their biological evolution. Furthermore, Itonaga $\mathrm{et}^{\mathrm{al}}{ }^{20}$ suggested that the proliferative component of CGCG would be represented by a mesenchymal stromal cell which had the capacity to differentiate along fibroblast/osteoblast lines.

Our findings suggest that these lesions may have the same histogenesis. The mononuclear stromal cells, both histiocytic and myofibroblastic are thought to be responsible for the behavior of these lesions, whereas the multinucleated cells are considered as reactive. Although the proliferative index is higher in mononuclear cells in PGCG than in CGCG and GCT, this does not reflect the aggressive histological behavior in PGCG. The dilemma on the nature of the giant cell lesions of the jaws still exists, and it is still not known whether these represents an inflammatory, reactive, infective, or neoplastic process.

Unfortunately, there was no correlation between the immunohistochemical markers and recurrence $(p=0.31)$. Recurrences can be affected by several factors such as clinical demographics (size of the lesion) and the complete surgical removal. Our study findings showed only large lesions $(>5 \mathrm{~cm})$ have tended to recur $(\mathrm{p}=0.001)$. However, no association was found between the studied markers and size of the lesions $(p=0.24)$. Other clinical factors demonstrated no difference in relation to recurrence $(p=0.17)$. It is still unknown why some of these lesions tend to recur. In fact, several attempts using histological, cytometric and immunoprofiling studies failed to establish the parameters that can be used to predict the clinical course of these lesions. ${ }^{21}$

Our study has a methodological limitation due to the relatively low number of examined tissue specimens and missing radiographic features.

In conclusion, despite the unexplained variation in the clinical behavior of PGCG, CGCG and GCT, these lesions shared similar immuno-profile and histological features. This might suggest that PGCG, CGCG and GCT are different variants for the same disease. Further studies using molecular pathology techniques are required to elucidate why some of these lesions behave aggressively than others.

\section{REFERENCE}

1. Jaffe HL. Giant cell reparative granuloma, traumatic bone cyst, and fibrous dysplasia of the long bones. Oral Surg Oral Med Oral Pathol 1953;6:159-175.

2. Whitaker SB, Waldron CA. Central giant cell lesions of the jaws. A clinical, radiologic, and histopathologic study. Oral Surg Oral Med Oral Pathol 1993;75:199-208.

3. Abrams B, Shear M. A histological comparison of the giant cells in the central giant cell granuloma of the jaws and the giant cell tumor of long bone. J Oral Pathol 1974;3:217-223.
4. Auclair PL, Cuenin P, Kratochvil FJ, Slater LJ, Ellis GL. A clinical and histomorphologic comparison of the central giant cell granuloma and the giant cell tumor. Oral Surg Oral Med Oral Pathol 1988;66:197-208.

5. Chuong R, Kaban LB, Kozakewich H, Perez-Atayde A. Central giant cell lesions of the jaws: A clinicopathologic study. J Oral Maxillofac Surg 1986;44:708-713.

6. Mangham DC. Giant cell tumor of bone and giant cellcontaining lesions of bone. In: Pathology of Bone and Joint Neoplasms. Philadelphia: W.B. Saunders; 1999. p. 304-329.

7. Sarode SC, Sarode GS. Cellular cannibalism in central and peripheral giant cell granuloma of the oral cavity can predict biological behavior of the lesion. J Oral Pathol Med. 2014;43(6):459-463.

8. Souza PE, Mesquita, RA, Gomez, RS. Evaluation of p53, PCNA, Ki-67, MDM2 and AgNOR in oral peripheral and central giant cell lesions. Oral Dis 2000;6:35-39.

9. Katsikeris N, Kakarantza-Angelopoulou E, Angelopoulos AP. Peripheral giant cell granuloma. Clinicopathologic study of 224 new cases and review of 956 reported cases. Int J Oral Maxillofac Surg 1988;17:94-99.

10. Eckardt A, Pogrel MA, Kaban LB, Chew K, Mayall BH. Central giant cell granulomas of the jaws. Nuclear DNA analysis using image cytometry. Int J Oral Maxillofac Surg 1989;18:3-6.

11. Regezi JA, Zarbo RJ, Ricardo VL. Muramidase, $\alpha-1$ antitrypsin, $\alpha-1$ antichymotrypsin, and S-100 protein immunoreactivity in giant cell lesions. Cancer 1987;59:64-68.

12. Lim L, Gibbins JR. Immunohistochemical and ultrastructural evidence of a modified microvasculature in the giant cell granuloma of the jaws. Oral Surg Oral Med Oral Pathol Oral Radiol Endod 1995;79:190-198.

13. O'Malley M, Pogrel MA, Stewart JC, Silva RG, Regezi JA. Central giant cell granulomas of the jaws: phenotype and proliferationassociated markers. J Oral Pathol Med 1997;26: 159-163.

14. de Souza PE, Paim JF, Carvalhais JN, Gomez RS. Immunohistochemical expression of p53, MDM2, Ki-67 and PCNA in central giant cell granuloma and giant cell tumor. J Oral Pathol Med 1999;28:54-58.

15. Peacock ZS, Jordan RC, Schmidt BL. Giant cell lesions of the jaws: Does the level of vascularity and angiogenesis correlate with behavior? J Oral Maxillofac Surg 2012; 70:1860-1866.

16. Cheng YY, Huang L, Kumta SM, Lee KM, Lai FM, Tam JS. Cytochemical and ultrastructural changes in the osteoclastlike giant cells of giant cell tumor of bone following bisphosphonate administration. Ultrastruct Pathol 2003;27:385-391.

17. Wulling M, Engels C, Jesse N, Werner M, Delling G, Kaiser E. The nature of giant cell tumor of bone. J Cancer Res Clin Oncol 2001;127:467-474.

18. Khiavi MM, Aghbali AA, Halimi M, Kouhsoltani M, Hamishehkar H. Immunohistochemical expression of Src protein in peripheral and central giant cell granulomas of the jaws. J Oral Maxillofac Pathol. 2013;17:358-362

19. Roholl P, Kleyne J, Pijpers H, Van Unnik J. Comparative immunohistochemical investigation of markers for malignant histiocytes. Hum Pathol 1985;16:763-771.

20. Itonaga I, Hussein I, Kudo O, Sabokbar A, Watt-Smith S, Ferguson D, et al. Cellular mechanisms of osteoclast formation and lacunar resorption in giant cell granuloma of the jaw. J Oral Pathol Med. 2003;32:224-231.

21. Vasconcelos RG, Vasconcelos MG, Guedes Queiroz LM. Peripheral and central giant cell lesions: Etiology, origin of giant cells, diagnosis and treatment. J Bras Patol Med Lab 2013;49:446-452. 